\title{
Influence of a prophylaxis paste on surface roughness of different composites, porcelain, enamel and dentin surfaces
}

\author{
Haktan Yurdaguven ${ }^{1}$ \\ Arzu Aykor ${ }^{1}$ \\ Emre Ozel ${ }^{2}$ \\ Hilmi Sabuncu ${ }^{3}$ \\ Mubin Soyman ${ }^{1}$
}

\section{ABSTRACT}

Objective: To investigate the effect of a prophylaxis paste on surface roughness of different composites, enamel, dentin and porcelain surfaces.

Methods: Three different composites (FiltekZ250/Group1, Filtek Supreme XT/Group2, Premise) Group3), enamel/Group4, dentin/Group5 and porcelain/Group6 samples were used in this study. All specimens were prepared flat by SiC discs and polished with a diamond polishing paste. The surface roughness measurements were determined with a profilometer after polishing linitial surface roughness). Prophylaxis paste was applied to the samples for 12 seconds, renewing every 6 seconds. After cleaning the samples, roughness values were measured again. Data were analyzed by Kruskal Wallis and Dunn's multiple comparison test. Wilcoxon test was performed for the comparison of the initial and final surface roughness values $(P<.05)$. The results were evaluated within the $P<.05$ confidence level.

Results: The initial and final surface roughness values $(\mu \mathrm{m})$ were determined as follows: Group1: $0.039 \pm 0.009$ and $0.157 \pm 0.018$, Group2: $0.023 \pm 0.005$ and $0.145 \pm 0.027$, Group3: $0.028 \pm 0.008$ and $0.109 \pm 0.012$, Group4: $0.024 \pm 0.006$ and $0.071 \pm 0.015$, Group5: $0.030 \pm 0.007$ and $0.143 \pm 0.029$, Group6: $0.024 \pm 0.006$ and $0.064 \pm 0.014$. Significant difference was determined between the initial and final values for all groups.

Conclusions: Composite and dentin surfaces were more affected by the application of prophylaxis paste than enamel and porcelain surfaces. The prophylaxis paste increased the surface roughness of all groups, but did not reach the bacterial retention roughness rate of $0.2 \mu \mathrm{m}$. (Eur J Dent 2012;6:1-8)

Key words: Prophylaxis paste, surface roughness, composite, enamel, dentin, porcelain

1 Department of Operative Dentistry, Faculty of Dentistry, Yeditepe University, Istanbul, TURKIYE.

2 Department of Operative Dentistry, Faculty of Dentistry, University of Kocaeli, Kocaeli, TURKIYE.

3 Department of Basic Medical Sciences, Yeditepe University, Istanbul, TURKIYE.
Corresponding author: Dr. Emre Ozel

Department of Operative Dentistry Faculty of Dentistry,

University of Kocaeli, Yuvacik, Kocaeli, TURKIYE.

Phone: 00902623442111

Fax: 00902623442202

E-mail: emreozel77ayahoo.com 


\section{INTRODUCTION}

A professional oral care provision includes the removal of plaque, calculus and staining. This procedure is repeated during every 3 or 6 month recalls. The finishing procedure may be an important factor on the long term oral hygiene performance and may be enhanced with the utilization of oral hygiene products such as prophylactic pastes. Dental practitioners prefer to apply a prophylaxis paste to polish the enamel surfaces after removing the calculus or to remove staining. During this procedure, teeth with an erosion, abrasion, abfraction lesion or restorations can also be polished inadvertently. Therefore, prophylactic pastes can affect the surface roughness of enamel, exposed dentin, cementum and restorative materials such as amalgam, composite, glass ionomer, resinmodified glass-ionomer, compomer or porcelain.

An ideal prophylactic paste should combine good cleaning ability with simultaneous polishing (morphological smoothing of dentin and enamel surfaces). In addition, the agent should cause minimal abrasion and surface roughness of dental hard tissues. ${ }^{1,2}$

The first influencing factor on surface roughness during cleaning procedures may be related to the composition, application force and application time of the prophylaxis paste. The second factor may be related to the dental hard tissue's and restoration's structure or composition, which is influenced by the inorganic and organic content of the hard tissues and the restorative material.

The content of prophylactic pastes are similar to dentifrices. Commercially available prophylaxis pastes are typically composed of a mixture of binder, humectant (to retain moisture and stabilizes the preparation), coloring agent, preservatives, fluoride, flavoring and a range of abrasive grades from coarse to fine. ${ }^{3}$ The abrasives are of various particle sizes and are categorized as fine (1-45 $\mu \mathrm{m})$, medium $(74-105 \mu \mathrm{m})$ or coarse-grade (74-177 $\mu \mathrm{m}$ ) prophylaxis pastes. ${ }^{3}$ These abrasives can increase the roughness of the dental hard tissues as well as the restoration surfaces, 4,5,6 but are necessary for effective plaque and stain removal. Improper hygiene techniques can reduce the functional and the esthetic life of composite restorations; ${ }^{7,8}$ and can cause gingival irritation and recurrent caries. ${ }^{9,10}$
Surface roughness is one of the most frequently used test methods to evaluate the effects of the prophylactic pastes both on dental hard tissues and restorative materials. 3,11,12,13,14 Several researches have focused on the surface roughness effect of the pastes on restorative materials or dental hard tissues separately.3,12,14,15,16 The purpose of this study was to investigate the effect of a prophylaxis paste on surface roughness of different type of resin composites, enamel, dentin and porcelain surfaces.

\section{MATERIALS AND METHODS}

Three light-cured resin composites, enamel, dentin and porcelain were used in the present study. The materials used in this study are exhibited in Table 1.

\section{Specimen Preparation}

Resin composite discs for Group 1, 2 and 3 were prepared $16 \mathrm{~mm}$ in diameter and $2 \mathrm{~mm}$ in thickness) in an acrylic mould and covered by a Mylar matrix strip. A glass slide of $1 \mathrm{~mm}$ thickness was placed over the strip before curing with a LED light curing unit (Elipar FreeLight 2, 3MESPE, St. Paul MN, USA) for 40 seconds per specimen. The intensity of the light source was $850 \mathrm{~mW} / \mathrm{cm}^{2}$.

The enamel (Group 4) and dentin (Group 5) specimens were obtained from the coronal part of the central incisors embedded parallel to the acrylic mould surface. The enamel group was prepared to a $4 \times 4 \mathrm{~mm}$ polished flat surface area. The teeth in the dentin group were abraded until a $6 \times 6 \mathrm{~mm}$ diamater dentin surface was obtained. In Group 6, porcelains (IPS-Empress II) were embedded into acrylic blocks with a diameter of 8 $\mathrm{mm}$ and a thickness of $2 \mathrm{~mm}$. Groups 4, 5 and 6 were polished with SiC discs (2500 grit) and diamond polishing paste $(1 \mu \mathrm{m})$. To reduce variability, all specimen preparations were performed by the same operator. The specimens were stored in deionized water for 24 hours.

\section{Surface Roughness Evaluation}

Surface roughness test was performed with a contact type profilometer (Perthometer M1 Mahr, Göttingen, Germany). Three measurements were taken at the center of each specimen in different directions. The cut-off value of surface roughness was $0.25 \mathrm{~mm}$. The sampling length for each 
measurement was $0.75 \mathrm{~mm}$. The avarage surface roughness ( $R$ a) values of each material were obtained.

After measuring the initial average surface roughness values, a prophylaxis paste (SeptodontDetartrine, Francel was applied for 12 seconds, renewing every 6 seconds. ${ }^{14}$ The second surface roughness (final surface roughness) values were obtained after cleaning the sample surfaces with an air-water spray.

\section{Statistical Analysis}

Kruskal Wallis and Dunn's multiple comparison test were used to compare the mean differences between materials for each group (Difference $=$ final - initial value). Wilcoxon test was performed for the comparison of the initial and final surface roughness values. The results were evaluated within the $\mathrm{P}<.05$ confidence level.

\section{Scanning Electron Microscope Evaluation}

Two representative specimens (treated with the prophylaxis paste and non-treated) of each group were prepared for the scanning electron microscope (SEM) (JEOL JSM 5200, Tokyo, Japan). Specimens were sputter coated with gold to a thickness of approximately $200 \AA \hat{\text { in }}$ a vacuum evaporator. SEM images of representative areas of the surfaces were taken at x500 magnifications.

\section{RESULTS}

The initial and final mean surface roughness values are exhibited in Table 2. Figures 1a, 2a, 3a, $4 a, 5 a$ and $6 a$ show the initial surface appearances of different materials, while figures $1 b, 2 b, 3 b, 4 b$, $5 b$ and $6 b$ present the final surfaces of the specimens for each group.

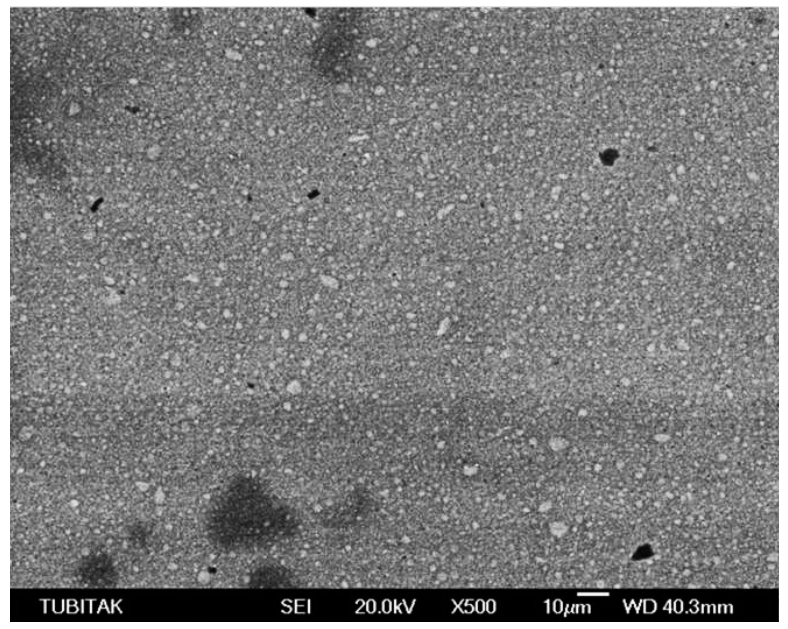

Figure 1a. Scanning electron micrograph of Filtek Z250.
Figure 1a exhibites the SEM image before the application of the prophylaxis paste to the hybrid composite, Filtek Z250. The structure of the resin composite is homogeneous in terms of inorganic filler and organic matrix [60\% (v/v), 66\% (w/w), 0.01-3.5 $\mu \mathrm{m}$ laverage particle size)]. After the treatment of Filtek Z250 with the prophylaxis paste, the inorganic part of the composite resin was more detectable (Figure $1 \mathrm{~b}$ ).

Figure 2 a presents the image of a nanofilled composite (Filtek Supreme XT) composed of small (nanofiller) and few large particles. The large particles could not be observed after the treatment [59.5\% (v/v), 78.5\% (w/w), 0.6-1.4 $\mu \mathrm{m}$ laverage particle size)] (Figure $2 b$ ).

Figure 3a shows the SEM image before the application of the prophylaxis paste to the nanofilled composite Premise. This resin composite includes mixed inorganic particles (small and large) of $71.2 \%(\mathrm{v} / \mathrm{v}), 84 \%(\mathrm{w} / \mathrm{w})$, and $0.4 \mu \mathrm{m}$ laverage particle size). Figure $3 b$ exhibites fine and irregular scratches on the composite surface after the treatment. Inorganic particles could not be observed.

Figure $4 a$ exhibites a smooth enamel surface before the application of the prophylaxis paste, while fine irregularities were detected after the treatment (Figure 4b).

Figure 5a presents the opened dentin tubular orifices before the application of the prophylaxis paste to the dentin surface. These tubuli disappeared after the application of the prophylaxis paste (Figure 5b). Coarse regular scratches on the dentin surface were observed.

Figure $6 \mathrm{~b}$ shows that the application of the prophylaxis paste to the porcelain does not change the surface dramatically compared with the initial appearance of the porcelain material (Figure 6a).

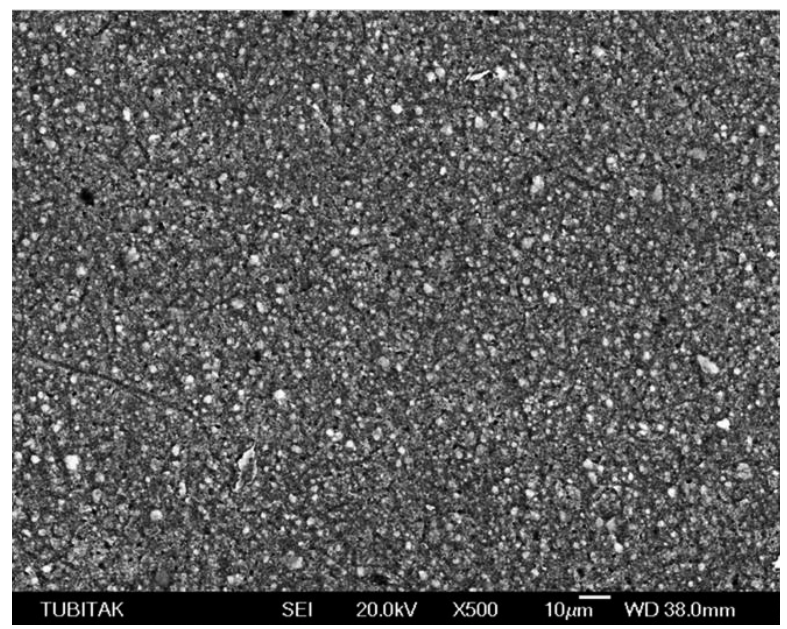

Figure 1 b. Scanning electron micrograph of Filtek Z250 detartrine group. 
Wilcoxon test showed that statistically significant differences exist between the initial and final surface roughness values for all groups $(P<.05)$. Kruskal Wallis and Dunn's multiple test were used to compare the differences (difference $=$ final - initial value) for each group (Table 3).

\section{DISCUSSION}

The oral cavity is constantly contaminated by many diverse microbial species. Most of these microorganisms, especially those which are responsible for caries (e.g., Streptococcus mutans and Lactobacillus spp.) and periodontitis (e.g., Actinobacillus actinomycetemcomitans and Porphyromonas gingivalis), can only survive in the mouth when they adhere to rough surfaces. The surface free energy can also play a role in bacterial adhesion and retention; however, studies suggested that the influence of the surface roughness overrules the influence of the surface free energy. ${ }^{17,18}$ The roughness of intraoral hard tissues and restorative materials can influence plaque retention and discoloration.

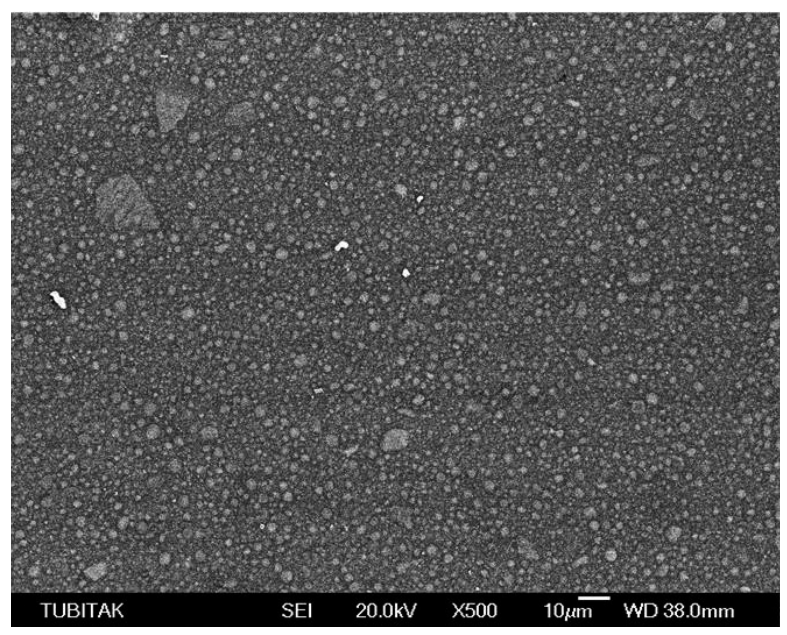

Figure 2a. Scanning electron micrograph of Filtek Supreme XT.

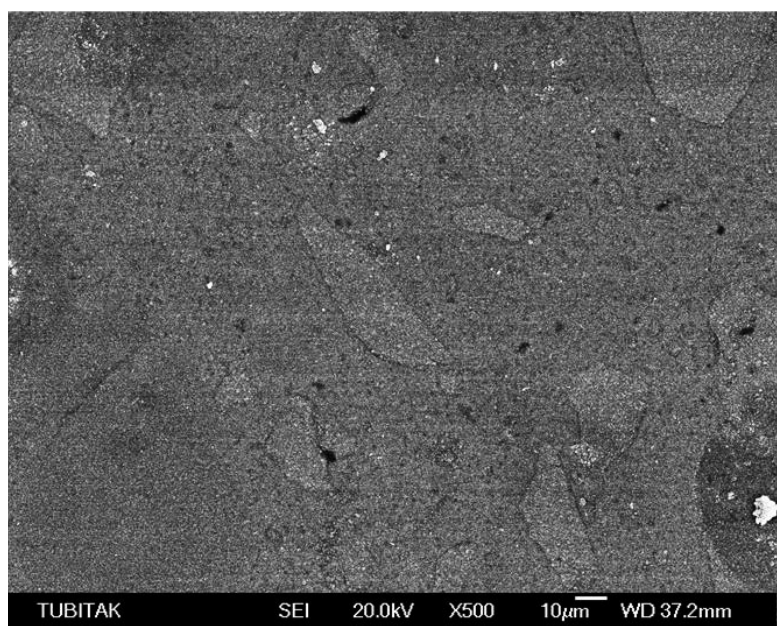

Figure 3a. Scanning electron micrograph of Premise.
This study evaluated the effects of a prophylaxis paste on surface roughness of three different composites, porcelain, enamel and dentin. Detartrine (Septodont, France) was used as a prophylaxis paste to polish the surfaces.

The surface roughness differences could be determined, when the surfaces are polished well. Therefore, the initial surface roughness of restorative materials is very important and should be close to the surface roughness of mylar strip. ${ }^{19}$ In the present study, all samples were polished with $600,1200,2500$ grid SiC and $1 \mu \mathrm{m}$ pumice to obtain standart initial test materials. Initial Ra values were in range of $0.023 \pm 0.005 \mu \mathrm{m}-0.039 \pm 0.009$ $\mu \mathrm{m}$. This data simulated the finishing under mylar strip. ${ }^{19}$

Surface roughness data (initial value) can be similar for different materials, but the type or characteristics of surface roughness (final value) can change. This may cause different colour change, marginal discoloration and bacterial retention to the surface. In addition, different abrasive wear of

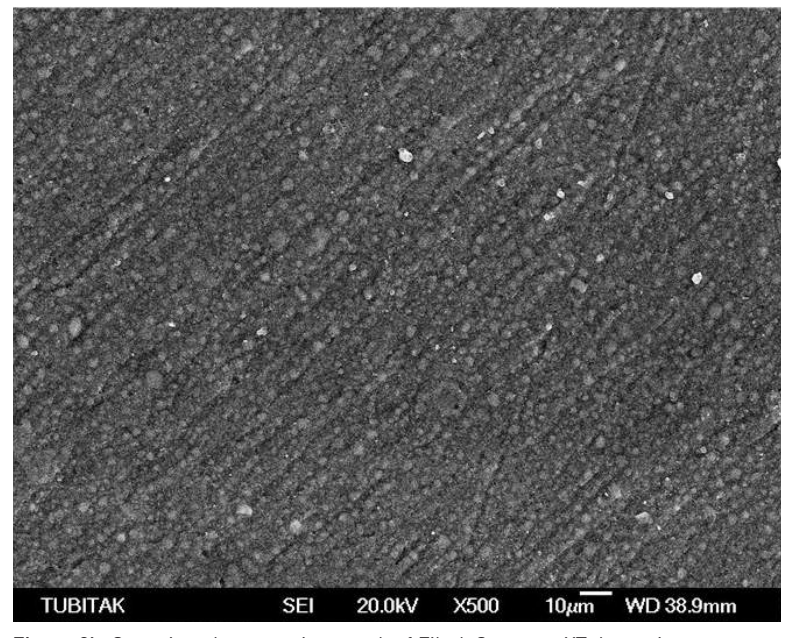

Figure 2b. Scanning electron micrograph of Filtek Supreme XT detartrine group.

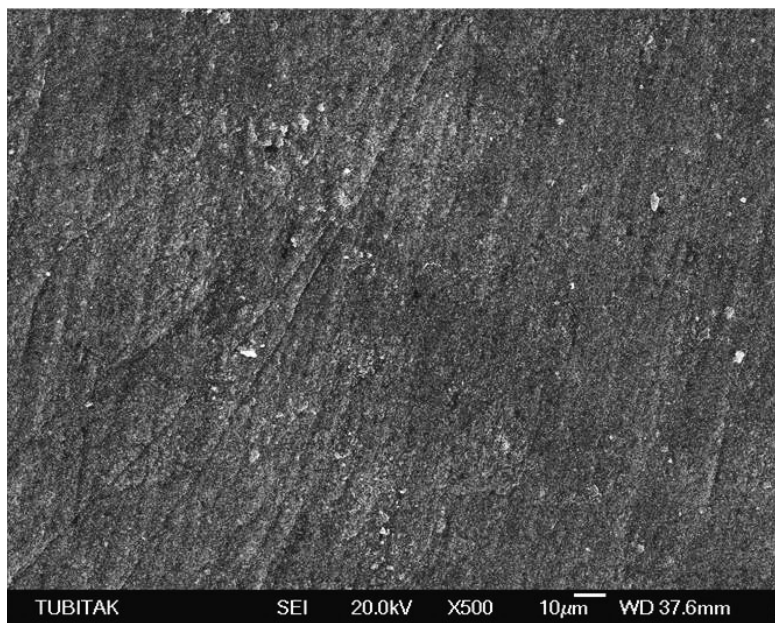

Figure $3 \mathrm{~b}$. Scanning electron micrograph of Premise detartrine group. 
the resin composite can also be observed. ${ }^{20}$ The obtained surface roughness data and the characteristics of the roughened surface in our study will be discussed in terms of the composition or structure of the material.

Filtek Z250 and Filtek Supreme XT did not show any statistical differences between the Ra (d) (difference of initial and final surface roughness), which might be caused by the same organic content of the two resin systems. The organic matrix used in Filtek Z250 is currently being used in Filtek Supreme XT Universal Restorative. The majority of TEGDMA has been replaced with a blend of
UDMA (urethane dimethacrylate) and Bis-GMA (6) (Bisphenol A polyetheylene glycol diether dimethacrylatel to reduce the polymerization shrinkage. Filtek Z250 showed that the inorganic part is more detectable after applying polishing paste for 12 seconds (Figure 1b). This can be interpreted as an abrasion of the organic matrix of the resin composite, which caused the projection of the inorganic fillers. Organic matrix of the composites is preferentially removed as the abrasives in prophylaxis pastes could be harder than the resin matrix and could even be similar in hardness to the fillers. ${ }^{21,22}$ Three-body wear lappling prophylaxis paste with

Table 1. Materials used in this study.

\begin{tabular}{llcc}
\hline Groups & $\mathrm{n}$ & Material & Manufacturer \\
\hline Group 1 & 10 & Filtek Z250 & 3MESPE, St. Paul MN, USA \\
Group 2 & 10 & Filtek Supreme XT & 3MESPE, St. Paul MN, USA \\
Group 3 & 10 & Premise & Kerr Corporation, Orange, CA, USA \\
Group 4 & 20 & Enamel & - \\
Group 5 & 20 & Dentin & - \\
Group 6 & 10 & Porcelain & Ivoclar-Vivadent, Schaan, Liechtenstein \\
\hline
\end{tabular}
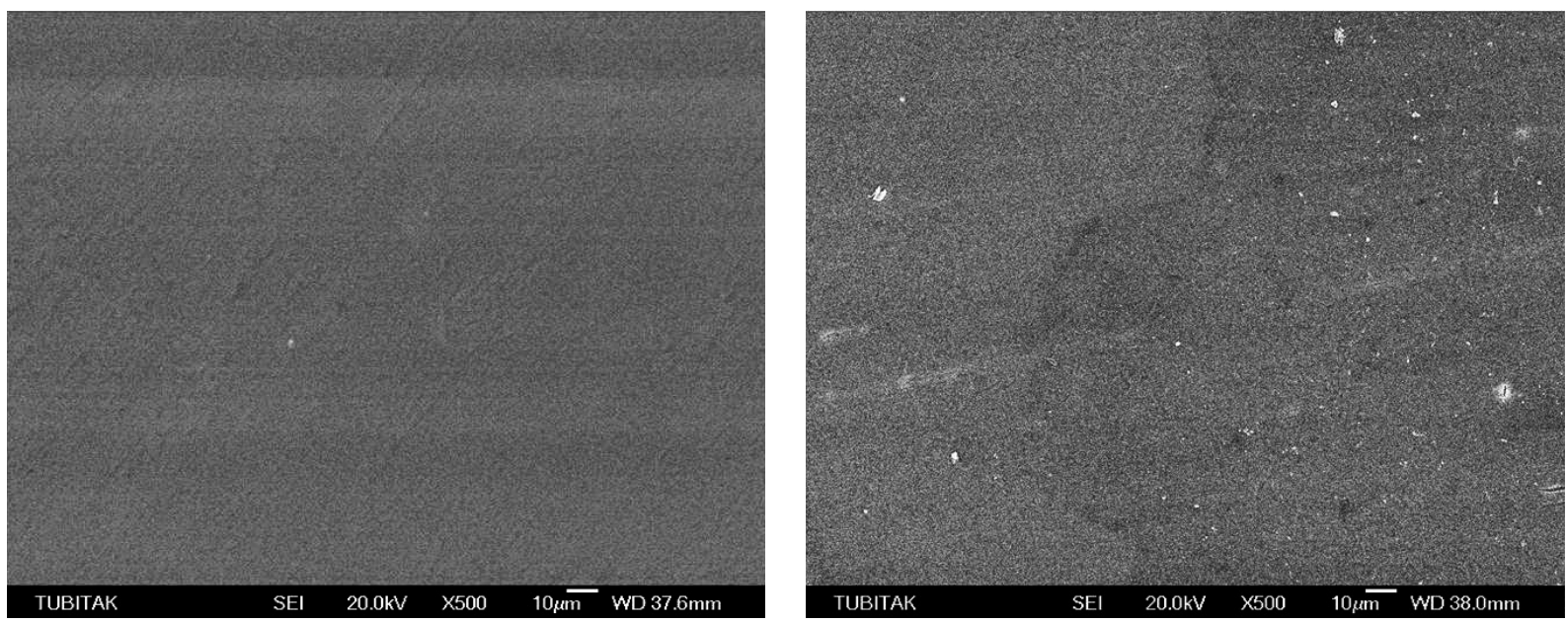

Figure 4a. Scanning electron micrograph of enamel.

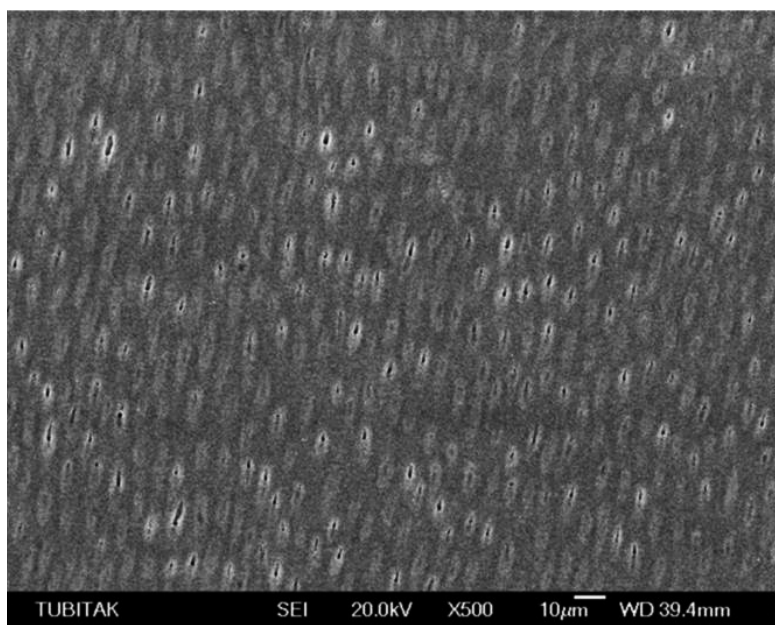

Figure 4b. Scanning electron micrograph of enamel detartrine group.

Figure 5a. Scanning electron micrograph of dentin.

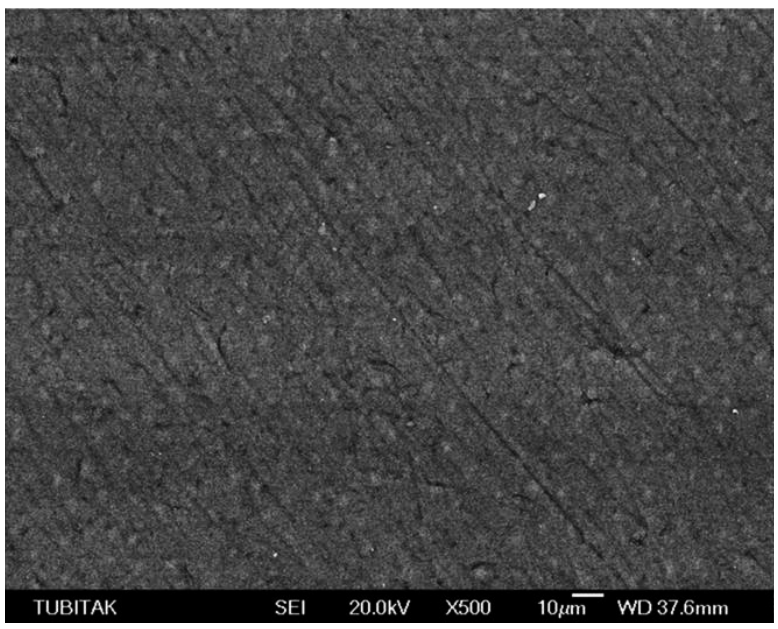

Figure $5 b$. Scanning electron micrograph of dentin detartrine group. 
a rotary instrument) involves the process of resin matrix loss between filler particles and subsequent dislodgement of the filler. ${ }^{23}$ Therefore, when the organic matrix is selectively removed, filler particles may be exposed and lead to a rough surface. ${ }^{21}$ Filtek $Z 250$ is a hybrid composite resin with a particle size of $0.6 \mathrm{~mm}$.

Filtek Supreme XT presented a similar surface roughness to Filtek Z250, however, this res- in showed parallel and coarse scratches on the composite surface after the treatment procedure (Figure $2 b$ ). The scratches can be observed due to the abrasion of the organic matrix and perhaps the removal of the inorganic particles. Filtek Supreme XT is a nanofilled hybrid composite and consists of different inorganic particles, which can be affected differently from the prophylaxis paste. Nanotechnology is used for products where critical com-

Table 2. The mean values and standart deviations.

\begin{tabular}{lcc}
\hline Groups & $\begin{array}{c}\text { Mean } \pm \text { SD } \\
\text { (initial measurement) }\end{array}$ & $\begin{array}{c}\text { Mean } \pm \text { SD } \\
\text { (final measurement) }\end{array}$ \\
\hline Group 1: Filtek Z250 & $0.039 \pm 0.009$ & $0.157 \pm 0.018$ \\
Group 2: Filtek Supreme XT & $0.023 \pm 0.005$ & $0.145 \pm 0.027$ \\
Group 3: Premise & $0.028 \pm 0.008$ & $0.109 \pm 0.012$ \\
Group 4: Enamel & $0.024 \pm 0.006$ & $0.071 \pm 0.015$ \\
Group 5: Dentin & $0.030 \pm 0.007$ & $0.143 \pm 0.029$ \\
Group 6: Porcelain & $0.024 \pm 0.006$ & $0.064 \pm 0.014$ \\
\hline
\end{tabular}

Table 3. Kruskal Wallis and Dunn's multiple comparison test evaluation.

\begin{tabular}{|ll}
\hline Dunn's multiple comparison test & Differences \\
\hline Filtek Z250 / Filtek Supreme XT & $\mathrm{P}>.05$ \\
\hline Filtek Z250 / Premise & $\mathrm{P}<.05$ \\
\hline Filtek Z250 / Enamel & $\mathrm{P}<.001$ \\
\hline Filtek Z250 / Dentin & $\mathrm{P}>.05$ \\
\hline Filtek Z250 / Porcelaine & $\mathrm{P}<.01$ \\
\hline Filtek Supreme XT / Premise & $\mathrm{P}<.05$ \\
\hline Filtek Supreme XT / Enamel & $\mathrm{P}<.001$ \\
\hline Filtek Supreme XT / Dentin & $\mathrm{P}>.05$ \\
\hline Filtek Supreme XT / Porcelaine & $\mathrm{P}<.001$ \\
\hline Premise / Enamel & $\mathrm{P}<.05$ \\
\hline Premise / Dentin & $\mathrm{P}<.05$ \\
\hline Premise / Porcelaine & $\mathrm{P}<.05$ \\
\hline Enamel / Dentin & $\mathrm{P}<.001$ \\
\hline Enamel / Porcelaine & $\mathrm{P}>.05$ \\
\hline Dentin / Porcelaine & $\mathrm{P}<.01$ \\
\hline
\end{tabular}

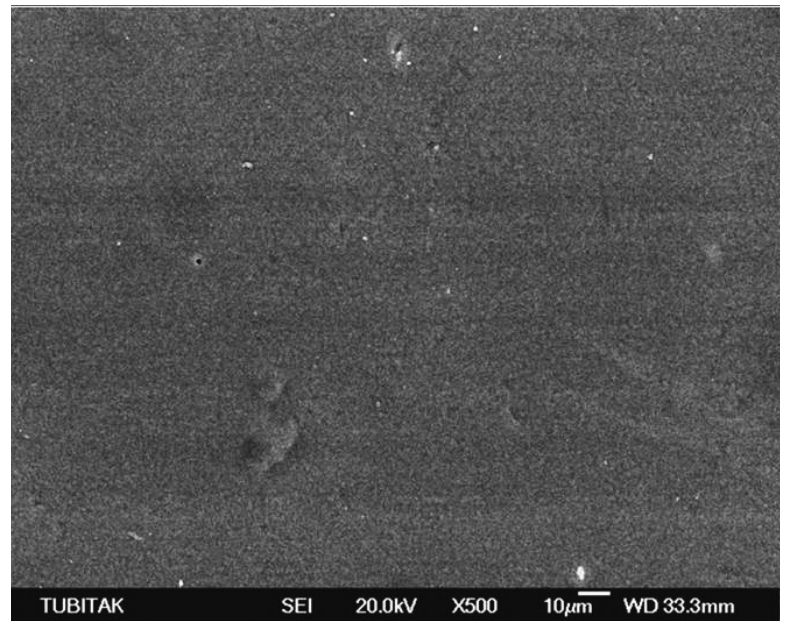

Figure 6a. Scanning electron micrograph of Empress II.

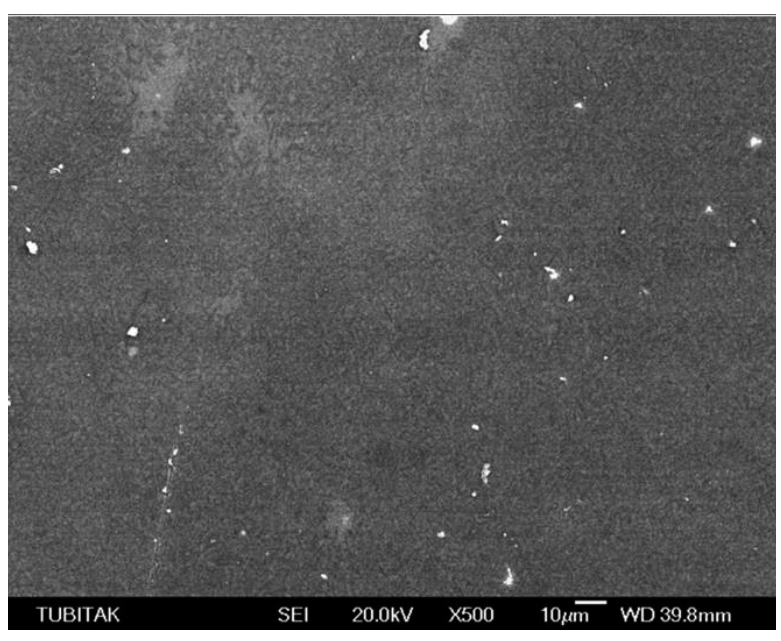

Figure 6b. Scanning electron micrograph of Empress II detartrine group.

European Journal of Dentistry 
ponent dimensions are in the range of 0.1 to 100 nanomers. It is claimed that the polish retention of 3MESPE Filtek Supreme XT Universal Restorative is similar to traditional microfilled type products. ${ }^{24}$

The surface roughness of Premise was statistically lower than the surface roughness of Filtek Z250 and Filtek Supreme XT. The resin composite Premise showed fine and irregular scratches on the composite surface after the treatment (Figure $3 b)$. Inorganic particles could not be observed. Premise resin composite contains 3 fillers, which are $0.02 \mu \mathrm{m}$ nanofiller, $0.04 \mu \mathrm{m}$ barium glass filler and pre-polymerized filler (PPF). This system is named Trimodal nano-filler technology. Premise exhibited a low roughness value after applying the prophylactic paste and showed better results than the other composites, which may be a result of this new trimodal system. Premise may be the choice for bacterial retentive areas especially for the restoration of Class II and V carious lesions due to the smoother resin surface. Our results support the claim of the manufacturer, that Premise is designed to offer high polishability.

Effect of hygiene procedures on enamel and dentin has been well investigated. ${ }^{1,12}$ The enamel group in our study showed fine irregularities after the treatment (Figure $4 \mathrm{~b}$ ). This can be due to the homogeneous structure of enamel, $98 \%$ of which is inorganic structure. The inorganic particle weight of the composites in comparison to enamel is maximum $83 \%$ which may be an explanation for the more affected composite surfaces (Group 1, 2 and 3).

Bollen et al ${ }^{25}$ reported that different prophylactic pastes have different effects on surface roughness. Lutz et al ${ }^{1}$ polished the enamel surfaces with pumice, which cause an increase on roughness linitial $R a$ value $=0.030 \mu \mathrm{m}$, final $R a$ value $=0.160$ $\mu \mathrm{m})$. In the present study, Detartrin applied enamel samples' Ra values were changed from $0.024 \pm 0.014 \mu \mathrm{m}$ to $0.071 \pm 0.020 \mu \mathrm{m}$. According to our results, Detartrin should be preferred against pumice during the stain removing procedures.

Dentin samples showed coarse regular scratches on the dentin surface after the treatment (Figure $5 b$ ). Orifices of the dentinal tubuli disappeared after the polishing procedure and a smear layer was produced. Long-term negative implications of this type of damage are unknown. ${ }^{12}$ Researches showed that extremely small amounts of tooth structure are removed as a result of polishing. ${ }^{12,21}$ On the positive side, polishing removes contaminated surface of dentin along with plaque and other debris, and increases the surface area. However, the scratching leaves loose dentin on the root surface and pumice particles embedded in the dentin. Both of these factors may interfere with chemical adhesion of the restorative materials. Further investigation is needed to clarify the role of fluor of the pumice polishing before placement of adhesives. ${ }^{12}$

Figure $6 \mathrm{~b}$ presented a regular surface after the treatment. So far, no research has been undertaken which evaluates the surface roughness of porcelain following cleaning procedures.

Composite restorations may require re-polishing after exposure to some hygiene maintenance procedures. ${ }^{14}$ Composite surface finishing procedures were evaluated by other authors. ${ }^{19,26,27}$ Roulet and Roulet-Mehrens ${ }^{21}$ recommended polishing conventional composites afterwards with aluminium silicate coated discs. Another area of investigation may be the evaluation of the effects of prophylaxis pastes on the roughened surfaces. The paste may probably have a possitive effect on the roughened surfaces.

The present study shows that the effect of prophylaxis pastes on surface roughness was material dependent. Filtek Z250, Filtek Supreme XT composites and dentin surfaces were more affected than the other surfaces after prophylaxis paste application. Premise exhibited a lower Ra value than the other two composites while higher than enamel and porcelain. Porcelain and enamel exhibited the lowest roughness differences after the application of the prophylaxis paste. Bacterial retention roughness rate has been reported as 200 $\mu \mathrm{m} .{ }^{25}$ The results showed that, in case of adequate surface preparation and finishing, the Ra values do not reach the bacterial retention rate of $200 \mu \mathrm{m}$ for all groups.

\section{CONCLUSIONS}

Within the limitations of this in-vitro study, it may be concluded that:

1-) Porcelain and enamel exhibited the lowest roughness differences after the application of the prophylaxis paste.

2-) Premise exhibited a low roughness value after applying the prophylactic paste and showed 
lower surface roughness differences than the other composites.

3-) Polishing paste application did not reach the bacterial retention rate of $0.2 \mu \mathrm{m}$ for all test materials. Therefore, this prophylaxis paste is acceptable for clinical applications.

\section{REFERENCES}

1. Lutz F, Sener B, Imfeld T, Barbakow F, Schupbach P. Comparison of the efficacy of prophylaxis pastes with conventional abrasives or a new self-adjusting abrasive. Quintessence Int 1993;24:193-201.

2. Barbakow F, Lutz F, Imfeld T. Relative dentin abrasion by dentifrices and prophylaxis pastes: Implications for clinicians, manufacturers and patients. Quintessence Int 1987;18:29-34.

3. Neme AL, Wagner WC, Pink FE, Frazier KB. The effect of prophylactic polishing pastes and toothbrushing on the surface roughness of resin composite materials in vitro. Oper Dent 2003;28:808-815.

4. Lutz F, Sener B, Imfeld T, Barbakow F, Schupbach P. Selfadjusting abrasiveness: a new technology for prophylaxis pastes. Quintessence Int 1993;24:53-63.

5. Goldstein RE, Garber DA, Schwartz CG, Goldstein CE. Patient maintenance of esthetic restorations. J Am Dent Assoc 1992;123:61-67.

6. Tanoue N, Matsumura H, Atsuta M. Wear and surface roughness of current prosthetic composites after toothbrush/dentifrice abrasion. J Prosthet Dent 2000;84:93-97.

7. Nash LB. Maximizing aesthetic restorations: the hygienist's role. Pract Periodontics Aesthet Dent 1991;3:17-18.

8. Nash LB. The role of the dental hygienist in caring for cosmetic-esthetic restorations. Dent Econ 1994;84:62-63.

9. Shintani H, Satou J, Satou N, Hayashihara H, Inoue T. Effects of various finishing methods on staining and accumulation of Streptococcus mutans HS-6 on composite resins. Dent Mater 1985;1:225-227.

10. Dunkin RT, Chambers DW. Gingival response to Class V composite restorations. J Am Dent Assoc 1983;106:482-484.

11. Neme AL, Frazier KB, Roeder LB, Debner TL. Effect of prophylactic polishing protocols on the surface roughness of esthetic restorative materials. Oper Dent 2002;27:50-58.

12. Christensen RP, Bangerter VW. Immediate and long-term in vivo effects of polishing on enamel and dentin. J Prosthet Dent 1987;57:150-160.

13. Maalhagh-Fard A, Wagner WC, Pink FE, Neme AM. Evaluation of surface finish and polish of eight provisional restorative materials using acrylic bur and abrasive disk with and without pumice. Oper Dent 2003;28:734-739.
14. Yap AUJ, Wu SS, Chelvan S, Tan ESF. Effect of hygiene maintenance procedures on surface roughness of composite restoratives. Oper Dent 2005;30:99-104.

15. Wu SS, Yap AU, Chelvan S, Tan ES. Effect of prophylaxis regimens on surface roughness of glass ionomer cements. Oper Dent 2005;30:180-184.

16. Yap AU, Yap SH, Teo CK, Ng JJ. Comparison of surface finish of new aesthetic restorative materials. Oper Dent 2004:29:100-104.

17. Quirynen M, Marechal M, Busscher HJ, Weerkamp AH, Darius $P L$, van teenberghe $D$. The influence of surface free energy and surface roughness on early plaque formation. An in vivo study in man. J Clin Periodontol 1990;17:138-144.

18. Quirynen M, Bollen CM. The influence of surface roughness and surface-free energy on supra- and subgingival plaque formation in man. A review of the literature. J Clin Periodontol 1995;22:1-14.

19. Turkun LS, Turkun M. The effect of one-step polishing system on the surface roughness of three esthetic resin composite materials. Oper Dent 2004;29:203-211.

20. Turssi CP, Ferracane JL, Serra MC. Abrasive wear of resin composites as related to finishing and polishing procedures. Dent Mater 2005;21:641-648.

21. Roulet JF, Roulet-Mehrens TK. The surface roughness of restorative materials and dental tissues after polishing with prophylaxis and polishing pastes. $J$ Periodontol 1982;53:257-266.

22. Serio FG, Strassler HE, Litkowski LJ, Moffitt WC, Krupa CM. The effect of polishing pastes on composite resin surfaces, A SEM study. J Periodontol 1988;59:837-840.

23. Bayne SC, Taylor DF, Heymann HO. Protection hypothesis for composite wear. Dent Mater 1992;8:305-309.

24. Technical product profile 3M ESPE Filtek Supreme universal restorative system Dental Products Laboratory, St. Paul, MN, USA.

25. Bollen, CM, Lambrechts $P$, Quirynen M. Comparison of surface roughness of oral hard materials to the threshold surface roughness for bacterial plaque retention $\mathrm{A}$ review of the literature. Dent Mater 1997;13:258-269.

26. Setcos JC, Tarim B, Suzuki S. Surface finish produced on resin composites by new polishing systems. Quintessence Int 1999;30:169-173.

27. Jung $M$, Bruegger $H$, Klimek J. Surface geometry of three packable and one hybrid composite after polishing. Oper Dent 2003;28:816-824. 